\title{
Structural Organization of the Laryngeal Motor Cortical Network and Its Implication for Evolution of Speech Production
}

\author{
Veena Kumar, ${ }^{1}$ Paula L. Croxson, ${ }^{2}$ and Kristina Simonyan ${ }^{1,3}$ \\ ${ }^{1}$ Department of Neurology, ${ }^{2}$ Department of Neuroscience, and ${ }^{3}$ Department of Otolaryngology, Icahn School of Medicine at Mount Sinai, \\ New York, New York 10029
}

The laryngeal motor cortex (LMC) is essential for the production of learned vocal behaviors because bilateral damage to this area renders humans unable to speak but has no apparent effect on innate vocalizations such as human laughing and crying or monkey calls. Several hypotheses have been put forward attempting to explain the evolutionary changes from monkeys to humans that potentially led to enhanced LMC functionality for finer motor control of speech production. These views, however, remain limited to the position of the larynx area within the motor cortex, as well as its connections with the phonatory brainstem regions responsible for the direct control of laryngeal muscles. Using probabilistic diffusion tractography in healthy humans and rhesus monkeys, we show that, whereas the LMC structural network is largely comparable in both species, the LMC establishes nearly 7-fold stronger connectivity with the somatosensory and inferior parietal cortices in humans than in macaques. These findings suggest that important "hard-wired" components of the human LMC network controlling the laryngeal component of speech motor output evolved from an already existing, similar network in nonhuman primates. However, the evolution of enhanced LMC-parietal connections likely allowed for more complex synchrony of higher-order sensorimotor coordination, proprioceptive and tactile feedback, and modulation of learned voice for speech production.

Key words: diffusion imaging; laryngeal control; motor cortex; neuroanatomy; speech; white matter pathways

\section{Significance Statement}

The role of the primary motor cortex in the formation of a comprehensive network controlling speech and language has been long underestimated and poorly studied. Here, we provide comparative and quantitative evidence for the significance of this region in the control of a highly learned and uniquely human behavior: speech production. From the viewpoint of structural network organization, we discuss potential evolutionary advances of enhanced temporoparietal cortical connections with the laryngeal motor cortex in humans compared with nonhuman primates that may have contributed to the development of finer vocal motor control necessary for speech production.

\section{Introduction}

Humans, unlike other primates, have a unique ability for extensive learning and communication of complex vocal behaviors such as speech and song. Nonhuman primates, on the other

\footnotetext{
Received Oct. 28, 2015; revised Feb. 9, 2016; accepted Feb. $28,2016$.

Author contributions: K.S. designed research; V.K., P.L.C., and K.S. performed research; K.S. contributed unpublished reagents/analytic tools; V.K., P.L.C., and K.S. analyzed data; V.K., P.L.C., and K.S. wrote the paper.

This work was supported by the National Institute on Deafness and Other Communication Disorders, National Institutes of Health (Grant R01DC01180 to K.S.) and the Charles H. Revson Foundation (P.L.C.). We thank Ziad Saad, Paul Taylor, and Giovanni Battistella for help with probabilistic tractography.

The authors declare no competing financial interests.

Correspondence should be addressed to Kristina Simonyan, MD, PhD, Department of Neurology, One Gustave L. Levy Place, Box 1137, Icahn School of Medicine at Mount Sinai, New York, NY 10029. E-mail: kristina.simonyan@mssm.edu.

DOI:10.1523/JNEUROSCI.3914-15.2016

Copyright $\odot 2016$ the authors $\quad 0270-6474 / 16 / 364170-12 \$ 15.00 / 0$
}

hand, are able to produce a wide range of species-specific calls, but have limited ability for the production of highly learned vocalizations such as speech (Jürgens, 2002; Simonyan, 2014). From the perspective of the motocortical output, the laryngeal component of voice production is controlled by the laryngeal motor cortex (LMC). The LMC regions in humans and nonhuman primates are considered to be functional homologs (Jürgens, 2002) because their stimulation yields an approximation (or adduction) of vocal folds to the midline of the larynx, which is independent of the movement of other body muscles (Foerster, 1936; Penfield and Boldrey, 1937; Sugar et al., 1948; Simonyan and Jürgens, 2002; Rödel et al., 2004; Coudé et al., 2011; Bouchard et al., 2013). Physiologically, vocal fold adduction is necessary not only for vocalization but also for such vital behaviors as breathing and swallowing, as well as abdominal straining during micturi- 
tion and delivery, lifting of heavy weights, forceful jumps, etc., in both human and nonhuman primate species. In the context of voice control, the LMC region of both species contains vocalization-related neurons (Penfield and Boldrey, 1937; Coudé et al., 2011; Bouchard et al., 2013), although nonhuman primates are well known to have limited control over their voluntary vocalizations compared with humans. It has been hypothesized that this limitation may be due to several factors, including cytoarchitectonic differences in the laryngeal motocortical representation between humans and nonhuman primates and the lack of direct descending projections from the LMC to the phonatory motoneurons of the brainstem (Simonyan, 2014).

Specifically, the human LMC is situated in area 4 of the primary motor cortex (Penfield and Boldrey, 1937; Rödel et al., 2004; Loucks et al., 2007; Brown et al., 2008; Bouchard et al., 2013; Simonyan, 2014), projects directly to phonatory motoneurons in the nucleus ambiguus (Kuypers, 1958; Iwatsubo et al., 1990), and its electrical stimulation elicits or disrupts production of a range of vocalizations (Penfield and Roberts, 1959; Bouchard et al., 2013; Breshears et al., 2015). In contrast, the functionally isolated LMC region in nonhuman primates is positioned in area 6 of the premotor cortex (Sugar et al., 1948; Hast et al., 1974; Jürgens, 1974; Simonyan and Jürgens, 2002; Coudé et al., 2011) and has only indirect projections to the nucleus ambiguus (Jürgens, 1976; Simonyan and Jürgens, 2003).

Despite these between-species differences, earlier neuroanatomical tract tracing studies showed that the monkey LMC establishes an extensive network with a large number of cortical and subcortical regions in nonhuman primates (Jürgens, 1976; Simonyan and Jürgens, 2002, 2003, 2005a, 2005b) similar to those activated during speaking and other laryngeal behaviors (Hickok and Poeppel, 2007; Simonyan et al., 2007; Price, 2012). However, within-group quantitative analysis and comparative knowledge about the LMC network organization in these two species remains scarce. As a result, it is unknown whether there are other neuroanatomical substrates in addition to the projections to the nucleus ambiguous that may contribute to the evolutionary ability of the human LMC for finer motor control of learned vocalizations.

The goal of this study was to use probabilistic diffusionweighted tractography to map and quantify within-group regional structural connectivity of the LMC in the macaque monkey and healthy humans. We localized the human LMC based on a meta-analysis of fMRI studies of speech production in healthy humans (Simonyan, 2014) and the macaque LMC based on direct electrical stimulation studies in the rhesus monkey (Simonyan and Jürgens, 2002, 2005a). We hypothesized that, as a functionally homologous region, the LMC would establish a similar structural network in both species for the support of such laryngeal behaviors as breathing, swallowing, and voice production. However, compared with nonhuman primates, we hypothesized that the human LMC developed a much enhanced network of structural connections with the brain regions responsible for higher-order sensorimotor processing and execution, which might have contributed to our ability to better integrate sensorimotor information for finer motor output of highly learned vocalizations such as speech and song.

\section{Materials and Methods}

Data acquisition

Humans. We acquired diffusion-weighted images (DWIs) in 21 healthy human volunteers ( 14 female/7 male, mean age $50 \pm 11$ years). All subjects were right-handed, monolingual native English speakers with no history of neurological, psychiatric, or laryngeal and speech problems. Written informed consent was obtained from each subject before participation. The study was approved by the Institutional Review Board of the Icahn School of Medicine at Mount Sinai.

Study participants were scanned on a 3T Philips Achieva MRI scanner with an 8-channel head coil using a sagittal T1-weighted 3D MPRAGE sequence $(172$ contiguous slices, voxel size $=1 \times 1 \times 1 \mathrm{~mm}, \mathrm{TR}=2300$ $\mathrm{ms}$, TE $=2.98 \mathrm{~ms}$, FOV $210 \mathrm{~mm})$. DWI data were acquired with the spin-echo EPI sequence ( 60 gradient directions, b-value $=1000 \mathrm{~s} / \mathrm{mm}^{2}$, voxel size $=2 \times 2 \times 2 \mathrm{~mm}, 68$ contiguous slices, $\mathrm{TR}=6700 \mathrm{~ms}, \mathrm{TE}=89$ $\mathrm{ms}, \mathrm{FOV}=240 \times 240 \mathrm{~mm}$ ). One volume without diffusion weighting was acquired as a b0 reference. To prevent head movements, subjects' heads were cushioned with padding in the coil.

Monkeys. DWI data were obtained in 10 healthy macaques (Macaca mulatta; 5 females/ 5 males; mean age 4.5 years, weight range $4.34-8.54$ $\mathrm{kg}$ ), which were scanned in sphinx position on a standard horizontal bore human 3T scanner with a 4-channel phased-array coil. Animals were sedated with ketamine intramuscularly, intubated, and anesthesia was maintained with isoflurane. Respiration rate, inspired and expired $\mathrm{CO}_{2}$ and isoflurane, core temperature, and $\mathrm{SpO}_{2}$ were monitored during scanning; monkeys were ventilated throughout the scanning session to maintain normal physiology. DWIs were acquired with EPI (60 isotropically distributed directions with no slice gap; $b=1000 \mathrm{~s} / \mathrm{mm}^{2}$; voxel size $1.0 \times 1.0 \times 1.0 \mathrm{~mm}, \mathrm{TR}=8300 \mathrm{~ms}$, TE $=102 \mathrm{~ms}, 56$ slices, field of view $96 \times 96$, acceleration factor $=2$ ). Six averages were acquired per monkey: three in the left-right phase-encode direction and three in the opposite phase-encode direction. This allowed for distortion correction along the phase encoding direction (Andersson et al., 2003), which was followed by registration, motion correction, and eddy current correction using the EDDY toolbox of FSL software (Smith et al., 2004). T1weighted images were acquired using a standard MPRAGE sequence with a resolution of $0.5 \times 0.5 \times 0.5 \mathrm{~mm}$. All protocols for animal care, MRI, and anesthesia were approved in accordance with the United Kingdom Animals (Scientific Procedures) Act of 1989.

\section{Data analysis}

Data preprocessing was conducted in the FMRIB Diffusion Toolbox (FDT) of FSL software, which included correction of eddy current distortions and subject movements by using an affine registration to a b0 reference volume. Diffusion tensors and associated parameters, including fractional anisotropy (FA) and eigenvectors, were calculated using nonlinear fitting in the Functional and Tractographic Connectivity Analysis Toolbox (FATCAT) of AFNI software. The uncertainty of FA and eigenvectors was calculated using the $3 \mathrm{dDW}$ Uncert tool, which uses a jackknife resampling algorithm with nonlinear fitting to build a pseudopopulation and to calculate bias and confidence intervals on the nonresampled estimators (Taylor and Saad, 2013).

Definition of the LMC seed in humans was based on the meta-analysis of 19 fMRI studies between 2000 and 2013 during production of glottal stops, syllables, and vowels with minimal linguistic meaning as simple vocal motor tasks, which identified 82 foci with the peaks of activation in the precentral gyrus in a total of 283 healthy subjects (Table 1) (Simonyan, 2014). For the consistency of meta-analysis, the Montreal Neurological Institute (MNI) coordinates reported in some of these studies were transformed into the Talairach-Tournoux (TT) space using GingerALE software (version 2.3). GingerALE uses a random effects algorithm to find agreement across subject groups and foci, incorporates variable uncertainty based on subject size, and limits the effect of a single experiment (Eickhoff et al., 2012). We used GingerALE to calculate an activation likelihood estimation (ALE) of brain function at each voxel based on the null distribution of the ALE statistic over foci at a familywise error-corrected $p=0.01$ with minimum cluster size of $200 \mathrm{~mm}^{3}$. The ALE-derived bilateral clusters with the peaks in the primary motor cortex (area 4p: left $-45,-14,33$ and right 44, -12, 35 in the TT standard space) were used as the LMC seed regions. Both the left and right seeds were inspected visually and, if necessary, confined to the primary motor cortex by masking out the excessive voxels in the neighboring somatosensory cortex. Each of these final LMC seeds were reflected into the opposite hemisphere and summed to create symmetrical left and right 
Table 1. Summary of studies included in ALE meta-analysis

\begin{tabular}{|c|c|c|c|c|c|c|c|c|}
\hline Study & $n$ & Task & Site & $x$ & $y$ & $z$ & $\mathrm{TT}$ & $\overline{M N I}$ \\
\hline \multirow[t]{2}{*}{ Tremblay et al., 2013} & \multirow[t]{2}{*}{39} & \multirow[t]{2}{*}{ Repetition of bisyllabic nouns } & $\mathrm{L}$ & -46 & -8 & 34 & $\mathrm{x}$ & \\
\hline & & & $\mathrm{R}$ & 49 & -12 & 30 & & \\
\hline \multirow[t]{2}{*}{ Eckers et al., 2013} & \multirow[t]{2}{*}{5} & \multirow[t]{2}{*}{ Non-meaningful consonant-vowel syllables or glottal stops in combination with vowels } & $\mathrm{L}$ & -46 & -4 & 44 & & $x$ \\
\hline & & & $\mathrm{R}$ & 54 & -6 & 46 & & \\
\hline \multirow[t]{4}{*}{ Grabski et al., 2012} & \multirow[t]{4}{*}{13} & \multirow[t]{4}{*}{ Vowel/i/ } & $\mathrm{L}$ & -60 & -4 & 18 & & $x$ \\
\hline & & & & -42 & -12 & 39 & & \\
\hline & & & $\mathrm{R}$ & 52 & -6 & 32 & & \\
\hline & & & & 49 & -7 & 36 & & \\
\hline \multirow[t]{2}{*}{ Peeva et al., 2010} & \multirow[t]{2}{*}{22} & \multirow[t]{2}{*}{ Repetitions of bisyllabic pseudowords } & $\mathrm{L}$ & -50 & -8 & 30 & & $x$ \\
\hline & & & $\mathrm{R}$ & 52 & 0 & 42 & & \\
\hline Simonyan et al., 2009 & 13 & Repetitions of the syllable /i?i/ (/i/ followed by glottal stop and followed by /i/) & $\mathrm{L}$ & -50 & -14 & 40 & & $\mathrm{x}$ \\
\hline & & & & -52 & -13 & 40 & & \\
\hline & & & $\mathrm{R}$ & 51 & -15 & 41 & & \\
\hline & & & & 50 & -14 & 40 & & \\
\hline Shuster, 2009 & 14 & Production of pseudowords & $\mathrm{L}$ & 48 & 10 & 31 & $x$ & \\
\hline & & & & 51 & 14 & 11 & & \\
\hline & & & $\mathrm{R}$ & -50 & 6 & 12 & & \\
\hline & & & & -43 & 5 & 26 & & \\
\hline Chang et al., 2009 & 35 & Meaningless consonant-vowel-consonant syllable production & $\mathrm{L}$ & -55 & -15 & 38 & & $x$ \\
\hline & & & $\mathrm{R}$ & 48 & -11 & 33 & & \\
\hline Olthoff et al., 2008 & 16 & Phonation without intonation & $\mathrm{L}$ & -18 & -30 & 58 & $\mathrm{x}$ & \\
\hline & & & & -47 & -12 & 45 & & \\
\hline & & & & -52 & 1 & 23 & & \\
\hline & & & $\mathrm{R}$ & 46 & -9 & 44 & & \\
\hline & & & & 15 & -31 & 57 & & \\
\hline & & & & 55 & 2 & 21 & & \\
\hline Riecker et al., 2008 & 9 & 64 bisyllabic pseudowords with /tet/ as the 2 nd unit & $\mathrm{L}$ & -48 & -6 & 36 & & $x$ \\
\hline & & & $\mathrm{R}$ & 48 & -6 & 33 & & \\
\hline Ghosh et al., 2008 & 10 & Mono-syllables & $\mathrm{L}$ & -54 & 2 & 20 & & $x$ \\
\hline & & & $\mathrm{R}$ & 54 & -8 & 48 & & \\
\hline & & & & 20 & -28 & 66 & & \\
\hline Brown et al., 2008 & 16 & Phonation using the schwa vowel or glottal stops & $\mathrm{L}$ & -38 & -14 & 32 & $x$ & \\
\hline & & & & -53 & 0 & 42 & & \\
\hline & & & & -40 & -10 & 30 & & \\
\hline & & & & -51 & 0 & 44 & & \\
\hline & & & $\mathrm{R}$ & 44 & -10 & 34 & & \\
\hline & & & & 53 & 4 & 42 & & \\
\hline & & & & 44 & -8 & 24 & & \\
\hline & & & & 50 & -2 & 37 & & \\
\hline Loucks et al., 2007 & 12 & Repetitions of glottal stop followed by /i/ & $\mathrm{L}$ & -44 & -10 & 39 & $x$ & \\
\hline & & & $\mathrm{R}$ & 36 & -8 & 28 & & \\
\hline Bohland and Guenther, 2006 & 13 & Simple and complex consonant-vowel sequences & $\mathrm{L}$ & -46 & -10 & 60 & & $x$ \\
\hline & & & & -44 & -18 & 64 & & \\
\hline & & & & -60 & 0 & 30 & & \\
\hline & & & $\mathrm{R}$ & 48 & 6 & 32 & & \\
\hline & & & & 56 & 8 & 32 & & \\
\hline & & & & 56 & 6 & 40 & & \\
\hline & & & & 50 & -14 & 60 & & \\
\hline & & & & 56 & 6 & 40 & & \\
\hline & & & & 62 & -4 & 42 & & \\
\hline & & & & 56 & 8 & 40 & & \\
\hline Soros et al., 2006 & 9 & Vowel "ah" & $\mathrm{R}$ & 60 & -4 & 42 & & $x$ \\
\hline & & & & 48 & -12 & 44 & & \\
\hline Terumitsu et al., 2006 & 18 & Phonation without articulatory tongue movements (/e/) and vocalization with tongue movement & $\mathrm{L}$ & -40 & -19 & 42 & & $x$ \\
\hline & & & & -56 & -2.8 & 21 & & \\
\hline & & & & -52 & -11 & 47 & & \\
\hline & & & & -54 & 0 & 23 & & \\
\hline & & & $\mathrm{R}$ & 51 & -11 & 38 & & \\
\hline & & & & 58 & -6 & 35 & & \\
\hline Wilson et al., 2004 & 10 & 23 repetitions of a meaningless mono-syllable & $\mathrm{L}$ & -51 & -11 & 46 & & $x$ \\
\hline & & & & -45 & -13 & 34 & & \\
\hline & & & & -56 & -4 & 22 & & \\
\hline & & & $\mathrm{R}$ & 56 & -8 & 44 & & \\
\hline & & & & 48 & -10 & 35 & & \\
\hline & & & & 60 & 0 & 20 & & \\
\hline
\end{tabular}


Table 1. Continued

\begin{tabular}{|c|c|c|c|c|c|c|c|c|}
\hline Study & $n$ & Task & Site & $x$ & $y$ & $z$ & TT & $\overline{M N I}$ \\
\hline \multirow[t]{4}{*}{ Riecker et al., 2002} & 12 & Production of "pa-pa-pa" & $\mathrm{L}$ & -59 & 1 & 22 & $x$ & \\
\hline & & & & -56 & -5 & 25 & & \\
\hline & & & $\mathrm{R}$ & 59 & -4 & 22 & & \\
\hline & & & & 62 & -2 & 25 & & \\
\hline \multirow[t]{5}{*}{ Riecker et al., 2000} & 10 & Production of "ta," "stra," and "pataka" & L & 39 & -15 & 22 & $\mathrm{x}$ & \\
\hline & & & & -54 & -6 & 27 & & \\
\hline & & & & -57 & -3 & 27 & & \\
\hline & & & $\mathrm{R}$ & 60 & 0 & 24 & & \\
\hline & & & & 51 & -6 & 21 & & \\
\hline \multirow[t]{8}{*}{ Lotze et al., 2000} & 7 & Production of "pa," "ta," "ka," and "pataka" & $\mathrm{L}$ & -48 & -10 & 52 & & $x$ \\
\hline & & & & -44 & -8 & 40 & & \\
\hline & & & & -46 & -8 & 26 & & \\
\hline & & & & -36 & -14 & 36 & & \\
\hline & & & $\mathrm{R}$ & 48 & -10 & 56 & & \\
\hline & & & & 64 & -16 & 28 & & \\
\hline & & & & 60 & -6 & 24 & & \\
\hline & & & & 54 & -8 & 42 & & \\
\hline
\end{tabular}

We identified 19 overt speech production fMRI studies dating between 2000 and 2013. Search terms in literature review were "syllable AND fMRI," "vowel AND fMRI," and "speech production AND fMRI." By choosing studies of the production of syllables/vowels with minimal linguistic meaning, we purported to identify simple voluntary laryngeal motor tasks rather than more complex tasks with wider cognitive involvement. A total of 82 candidate foci from 283 healthy subjects were chosen, which localized to the primary motor cortex within the precentral gyrus. MNI standard space coordinates were transformed into TT space for analysis with ALE.

LMC masks. This approach helped to maximize the comparability of the results between the left and right hemispheres while minimizing the possible effect of different peak locations. Binary LMC masks in the standard TT space of AFNI software were transformed into each individual anatomical space using AFNI's nonlinear registration tool and affine registered to transform from the subject's anatomical space to the corresponding diffusion space.

Definition of the LMC seed in macaques was determined using the stereotactic coordinates from electrical stimulation and the neuroanatomical tract tracing studies of the LMC in the rhesus monkey (Simonyan and Jürgens, 2002, 2005a). Four millimeter bilateral spherical masks were constructed around the reported stimulation and injection site (Fig. 1B), which was located in the cytoarchtectonic area 6VR (Paxinos et al., 2000) and yielded isolated vocal fold adduction when electrically stimulated. The coordinates of the macaque LMC seeds were left $-21.5,7.5,0.5$ and right 22.0, 7.0, 0.5 in the monkey MNI standard space, which corresponded to bregma $03.60 \mathrm{~mm}, \mathrm{DV}-30 \mathrm{~mm}$, from midline $24 \mathrm{~mm}$ according to the atlas of the rhesus monkey brain (Paxinos et al., 2000). We used AFNI affine registration to transform these masks from each macaque's anatomical space to the corresponding diffusion space for further processing.

Target masks of the LMC were selected as cortical and subcortical regions, which are known to receive/send direct LMC connections based on neuroanatomical tract tracing studies of the LMC in the rhesus monkey (Simonyan and Jürgens, 2002, 2003, 2005a, 2005b) relevant to voice control in humans and monkeys (Jürgens, 2002; Simonyan et al., 2009; Price, 2012; Fuertinger et al., 2015; Simonyan and Fuertinger, 2015). These target regions included the primary somatosensory cortex (areas $3 \mathrm{a}, 3 \mathrm{~b}, 1$, and 2), supplementary motor area (SMA, area 6), inferior frontal gyrus (IFG, areas 44 and 45), inferior parietal lobule (IPL, area 40, $\mathrm{PF}$ ), superior temporal gyrus (STG, areas 41,42 , and 22), anterior cingulate cortex (perigenual ACC, areas 25, 33, 24, and 32), midcingulate cortex (MCC or posterior ACC, areas 33', 24',24d, and 32'), basal ganglia (putamen, caudate nucleus, and globus pallidus, internal and external subdivisions), and thalamus (all subdivisions). All target masks were drawn based on their regional boundaries, including all subdivisions of a region, wherever appropriate. In humans, the target masks were defined based on the cytoarchitectonic maximum probability and macrolabel atlas (Eickhoff et al., 2005) implemented in AFNI software. In macaques, cortical masks were defined based on previous studies (Lewis and Van Essen, 2000), and subcortical regions were defined based on the rhesus monkey atlas (Paxinos et al., 2000), both implemented in Caret software (Van Essen et al., 2001) and registered into macaque standard MNI space (Frey et al., 2011).

All masks in both humans and macaques were first registered from the standard space to individual subject space using nonlinear registration,
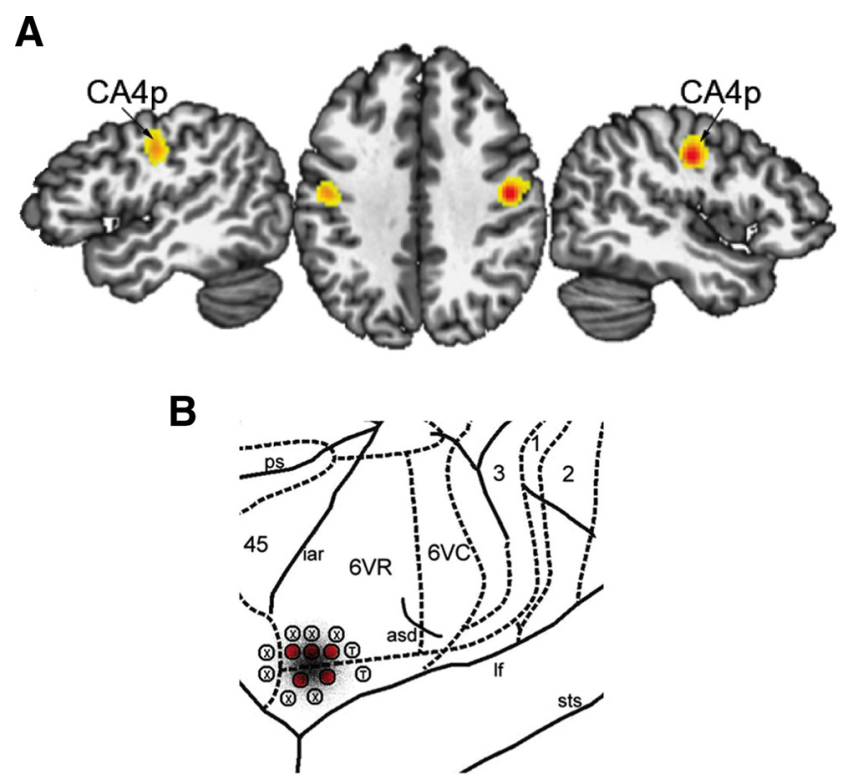

Figure 1. The location of the LMC in humans and macaque monkeys. $\boldsymbol{A}$, In humans, the LMC was identified based on ALE meta-analysis of $19 \mathrm{fMRI}$ studies (Table 1), with the significant bilateral peaks of ALE activation in cytoarchitectonic area $4 p$ (CA4p, left $-45,-14,33$, and right $44,-12,35$ in the TT standard space; adapted from Simonyan, 2014). $\boldsymbol{B}$, Location of the macaque LMC was based on direct stimulation of the motor cortex, which corresponded to cytoarchitectonic area 6VR at bregma $03.60 \mathrm{~mm}, \mathrm{DV}-30 \mathrm{~mm}$, from midline $24 \mathrm{~mm}$ (Paxinos et al., 2000); bilateral $4 \mathrm{~mm}$ seeds were placed around the coordinates left $-21.5,7.5,0.5$ and right 22.0,7.0,0.5 in the monkey MNI standard space (adapted from Simonyan and Jürgens, 2005b). An injection site at the LMC site for neuroanatomical tract tracing is superimposed in black. Red encircled $L$ indicates isolated bilateral vocal fold adduction elicited with electrical stimulation; $T$, tongue movements; $X$, no response.

followed by affine registration from the subject anatomical space to individual diffusion space. All masks were examined visually to avoid possible overlap and inflated to intersect with white matter (FA threshold of 0.1 to prevent excessive inflation) as required by the AFNI's FATCAT probabilistic tractography algorithm. The final masks were checked visually for correct alignment and registered back from the diffusion space to standard space for between-subject comparisons using AFNI nonlinear registration.

Probabilistic tractography was performed using the FATCAT toolbox in AFNI software in both humans and macaques. FATCAT uses the 
streamline tracking method FACTID (fiber assessment by continuous tracking including diagonals), which improves on existing FACT methods by allowing tracts to propagate diagonally between voxels, decreasing numerical errors, noise sensitivity, and increasing efficiency (Taylor et al., 2012). Using the uncertainty measurements, we computed pairwise connections between the LMC and all target masks by using Monte Carlo iterations of whole-brain tractography estimates (Taylor et al., 2012; Taylor and Saad, 2013). Whole-hemispheric inclusion masks were used to analyze the left- and right-hemispheric tracts separately. Because tractography might lead to a host of spurious connections, we applied a two-step thresholding approach at different levels of data processing. First, the quantitative fraction threshold was set at minimum of 50 tracts per voxel over all Monte Carlo iterations when computing individual LMC-totarget pairwise connections, which removed the bottom $10 \%$ of tracts in all resultant individual images. This was followed by thresholding the group probabilistic maps of all LMC-to-target tracts to remove the bottom $10 \%$ of subject variability within each group.

In vivo probabilistic diffusion-weighted tractography has been accepted as a valid method for the assessment of white matter connectivity due to its capability of modeling multiple fiber directions per voxel and providing realistic estimates of the wiring strength of white matter projections (Johansen-Berg and Behrens, 2006; Jbabdi et al., 2013; van den Heuvel et al., 2015). However, as the field of diffusion imaging moves from validating known connections to attempting to discover new ones (e.g., differences between macaque tract tracing findings and human connections), we note some of the limitations of the white matter tractography technique (Campbell and Pike, 2014; Thomas et al., 2014). Although it is excellent for defining the gross structure of tracts, tractography is somewhat limited in areas where there is the most uncertainty in the human brain. Tractography is not limited to monosynaptic connections nor does it allow us to infer directionality of the connections, making it important to refer back to tract tracing studies during interpretation. In addition, tractography may be challenging in the brain regions of high fiber complexity (for a more detailed discussion, see Jbabdi and Johansen-Berg, 2011). For example, it has been suggested that tracking white matter fibers into the cortex to find their exact termination may be further limited by the complexity added by local corticocortical connections passing parallel to the cortex (Reveley et al., 2015). Taking into account these limitations, recent studies have shown that probabilistic tractography, which greatly capitalizes on the quantitative potential of assessing the probability of a connection between the two regions, can be applied successfully in both human and nonhuman primate species to draw conclusions not only about the nonhuman primate brain in a validated model but also the human brain and how it may differ from that of the nonhuman primate.

Another caveat of white matter tractography is the likelihood of an excessively large number of tracts to targets surrounding the seed region and a disproportionately small number of tracts to targets further away. Although targets surrounding a seed are more likely to have anatomical connections due to the tracking algorithm, they are easier to pick up than tracts propagating farther away, resulting in distance bias. Similarly, more tracts may propagate to larger targets. Therefore, to correct for differences in target size and distance within each species, we divided the resulting number of tracts to each region by target volume and multiplied by the minimum Euclidean distance between the regional masks (Cerliani et al., 2012; Colby et al., 2012). Minimum Euclidean distance was calculated using Nipype neuroimaging tools. The corrected number of tracts was then used for final statistical analysis. To calculate the proportion of tracts from the LMC to each target within each species, the corrected number of tracts was divided by the sum of all LMC tracts and multiplied by 100 . Strong connections were classified as those in which representation in the LMC tract network was $>10 \%$; moderate connections represented $1-10 \%$ and connections $<1 \%$ were considered weak.

Another limitation of tractography compared with neuroanatomical tract tracing, is that it is prone to generating false-positive tracts. We therefore tested the specificity of our main results by performing additional probabilistic tractography between the LMC and the primary visual cortex (area 17), which is one of the only few brain regions that does not receive or send direct projections to the LMC as revealed by neuro- anatomical tract tracing studies in the macaque monkey (Simonyan and Jürgens, 2002, 2005a). After applying the same probabilistic tractography processing steps as used in the main study, we found that, of 21 humans, only one subject showed sparse, unilateral white matter connections between the LMC and area 17 of the visual cortex. This finding indicates that the LMC tractography has a much lower probability, if any at all, of connections to the target visual cortex, to which there is a known absence of tracer connections, thus strengthening the specificity of our main results.

\section{Statistical analysis}

For quantitative within-group analysis of the human and macaque LMC networks, we used the corrected number of tracts reaching each LMC target to conduct two separate within-group two-factor analyses of variance (ANOVA), with target brain regions and hemispheric site as factors at a corrected $p \leq 0.05$. If the main effect of target brain regions was significant, the follow-up post hoc univariate $F$ tests examined the significance of each LMC-target connection within the LMC network at $p \leq$ 0.004 to correct for multiple comparisons. Finally, if the hemispheric site or its interaction with the target regions was significant on initial ANOVA, the follow-up paired $t$ tests assessed the tract lateralization at $p \leq 0.05$. In addition, hemispheric lateralization of LMC connections was assessed using a laterality index (LI), which was calculated as follows: (corrected number of tracts in the left hemisphere - corrected number of tracts in the right hemisphere)/(corrected number of tracts in the left hemisphere + corrected number of tracts in the right hemisphere) (Seghier, 2008; Simonyan et al., 2009). A positive LI was interpreted as left-hemispheric lateralization and a negative LI indicated righthemispheric lateralization of the tract.

\section{Results}

Consistent with previous neuroanatomical tracing studies of the LMC in macaques (Simonyan and Jürgens, 2002, 2003, 2005a, 2005b) and unrestricted diffusion tractography in humans (Simonyan et al., 2009), the LMC tracts reached all examined cortical and subcortical target regions, establishing qualitatively comparable LMC structural networks in both species (Figs. 2, 3, Table 2). Specifically, the LMC was densely connected with the primary somatosensory cortex and IFG, as well as with subcortical structures such as the putamen, globus pallidus, and thalamus (Figs. 2, 3). However, despite these overall similarities, we identified several regional and hemispheric differences in LMC connectivity within humans and macaques, respectively.

Quantification of the proportion of projections from the LMC to each target (as a corrected number of tracts to each target/the sum of all tracts from the LMC) within each species revealed that the majority of LMC tracts in humans were connected to the IPL (48.9\%), then primary somatosensory cortex (22.2\%), and area 44 of the IFG (12.9\%) (Fig. 4A). A moderate proportion of connections reached area 45 of the IFG (5.1\%), STG (4.7\%), putamen $(3.3 \%)$, globus pallidus (1.5\%), and SMA (1.1\%). Only a very low proportion of projections were found in the cingulate cortex $(0.1 \%)$, caudate nucleus $(0.03 \%)$, and thalamus $(0.2 \%)$. ANOVA found significant effect of the target regions $\left(F_{(10)}=\right.$ $70.1, p \leq 0.001)$ and their interaction with the hemispheric site $\left(F_{(10)}=3.8, p=0.021\right)$ in humans. Within the LMC network, post hoc analysis further identified statistical significance of the bilateral IFG (left and right area 44: $F_{(20)} \geq 19.0, p \leq 0.0005$; left area 45: $\left.F_{(20)}=10.9, p=0.004\right)$, primary somatosensory cortex (left and right $F_{(20)} \geq 153.9, p \leq 0.0005$ ), IPL (left and right $F_{(20)}$ $\geq 78.8, p \leq 0.0005$ ), and STG (left and right $F_{(20)} \geq 28.8, p \leq$ $0.0005)$. Trends to significance were also found in the left area 45 $\left(F_{(20)}=6.9, p=0.016\right.$ ), bilateral SMA (left and right $F_{(20)} \geq 5.0$, $p \leq 0.037$ ), putamen (left and right $F_{(20)} \geq 8.6, p \leq 0.009$ ), caudate nucleus (left and right $F_{(20)} \geq 6.4, p \leq 0.020$ ), and right globus pallidus $\left(F_{(20)}=5.1, p=0.034\right)$. Paired $t$ test assessing the 

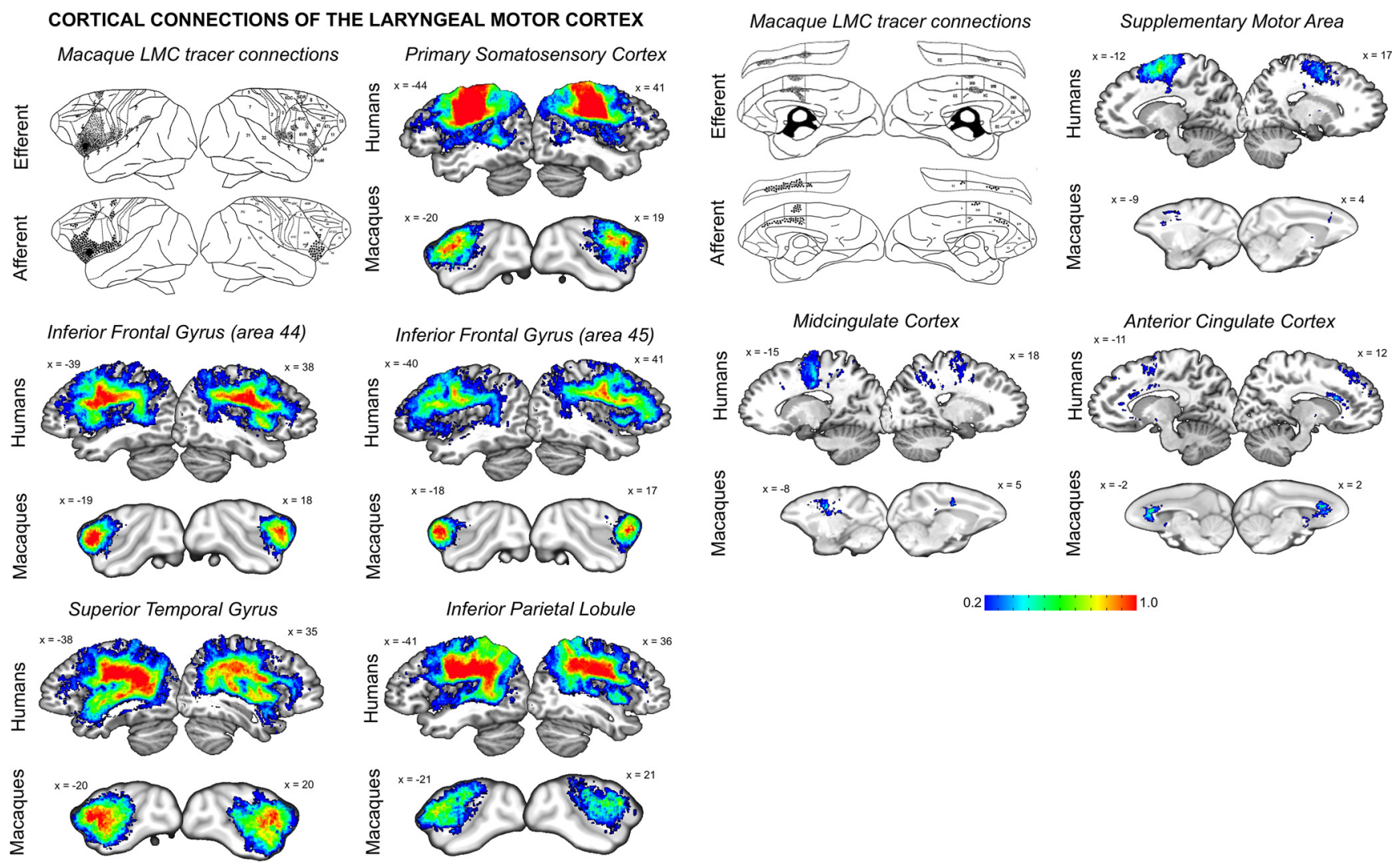

Figure 2. Probabilistic maps of structural connectivity between the LMC and cortical regions known to be involved in voice control. Probabilistic tractography maps in humans and macaques are depicted on a series of sagittal brain slices in the standard space. These maps illustrate the spectrum of connection likelihood, or probability, of the tract distribution across subjects within each group. The corresponding color bar shows the probabilistic distribution of structural connections having a pathway pass through a given brain region thresholded from 0.2 (a low connection probability) to 1 (a high connection probability) in both species. For a visual comparison between the findings of probabilistic tractography and neuroanatomical tract tracing of the LMC, schematic diagrams of the rhesus monkey cortex show the lateral and medial views of each hemisphere, with lines and dots indicating probabilistic distribution of the anterograde and retrograde projections of the macaque LMC (adapted from Simonyan and Jürgens, 2002, 2005a). The corresponding MNI coordinates of the center of gravity of maximal tract probability within each target region in each species is given in Table 2 .

hemispheric lateralization of LMC target regions found area 44 to show greater right-hemispheric connectivity $(t=2.523, p=$ $0.020)$ and the SMA to show greater left-hemispheric connectivity $(t=2.50, p=0.021)$ (Fig. $4 C)$. The STG trended toward greater connectivity in the left hemisphere $(t=1.93, p=0.068)$.

Calculating the proportion of tracts from the LMC to each target region in macaques, we found that the majority of tracts from the macaque LMC connected to area $44(43.1 \%)$, then the putamen (13.9\%), and area $45(12.6 \%)$ (Fig. $4 B)$. A moderate proportion of connections reached the STG (7.2\%), globus pallidus (6.7\%), IPL (5.6\%), primary somatosensory cortex (5.1\%), caudate nucleus $(2.1 \%)$, and thalamus $(2.8 \%)$. Fewer connections projected to the cingulate cortex $(0.79 \%)$ and SMA $(0.07 \%)$. Within-group ANOVA showed a significant main effect of the target regions $\left(F_{(11)}=40.1, p \leq 0.001\right)$ only. The follow-up univariate $F$ tests showed significance of the LMC connections with the bilateral IFG (left and right area 44: $F_{9} \geq 147.4, p \leq$ 0.0005; right area 45: $\left.F_{(9)}=19.3, p=0.002\right)$ and right STG $\left(F_{(9)}\right.$ $=36.2, p \leq 0.0005$ ) (Fig. 4A). Trends toward the significance were observed in the bilateral primary somatosensory cortex $\left(F_{9}\right.$ $\geq 9.7, p \leq 0.013)$ and putamen $\left(F_{9} \geq 8.2, p \leq 0.019\right)$, the left area $45\left(F_{(9)}=10.7, p \leq 0.010\right)$ and IPL $\left(F_{(9)}=8.8, p \leq 0.016\right)$, and right ACC $\left(F_{(9)}=6.61, p \leq 0.030\right)$. Because the initial ANOVA did not find any significant effects for hemispheric site $\left(F_{(9)}=\right.$ $0.16, p=0.70)$ or its interaction with the target regions $\left(F_{(11)}=\right.$
$0.99, p=0.46$; Fig. $4 D$ ), the hemispheric lateralization of the LMC connections was not further tested statistically.

\section{Discussion}

Several hypotheses have been put forward attempting to explain the evolutionary changes from monkeys to humans that potentially led to enhanced LMC functionality for finer motor control of speech production. First, functionally homologous LMC in humans and nonhuman primates is located in the different cytoarchitectonic subdivisions of the motor cortex (Penfield and Boldrey, 1937; Sugar et al., 1948; Hast et al., 1974; Simonyan and Jürgens, 2002; Rödel et al., 2004; Bouchard et al., 2013). Second, in contrast to its functional homolog in nonhuman primates, the human LMC has direct connections to the nucleus ambiguus of the brainstem (Kuypers, 1958; Iwatsubo et al., 1990), allowing it to bypass the reticular formation and modulate laryngeal motoneurons directly (Simonyan and Jürgens, 2003). Finally, overlap between the LMC and motor areas involved in expiration may have allowed for the convergence of expiration, phonation, and articulation, facilitating better control of complex vocalizations (Ramsay et al., 1993; Loucks et al., 2007; Brown et al., 2009). It is assumed that a combination of these factors in the course of hominid evolution might have led to a caudal "shift" of the LMC representation from the "old" motor cortex to the "new" motor cortex (Rathelot and Strick, 2009), establishing the direct access 


\section{SUBCORTICAL CONNECTIONS OF THE LARYNGEAL MOTOR CORTEX}

\section{Macaque LMC tracer connections}
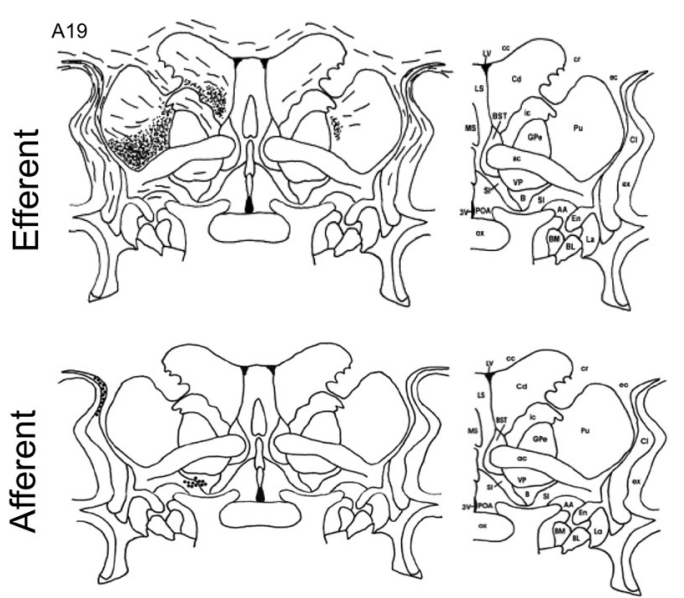

Caudate nucleus
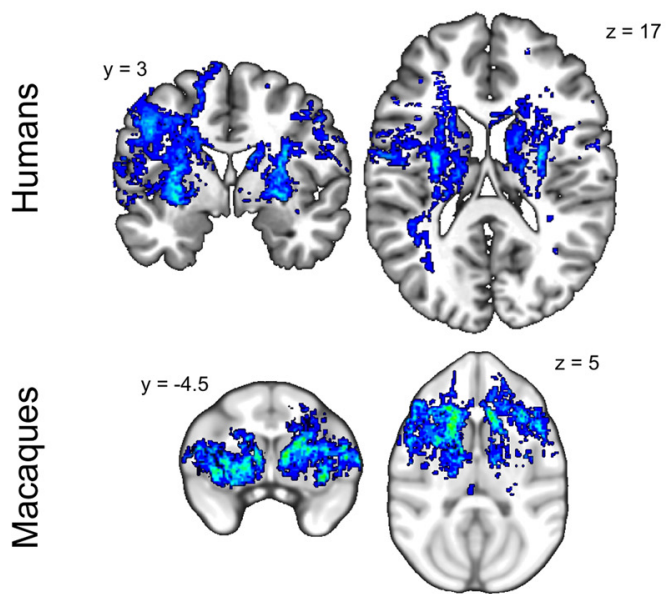

Putamen
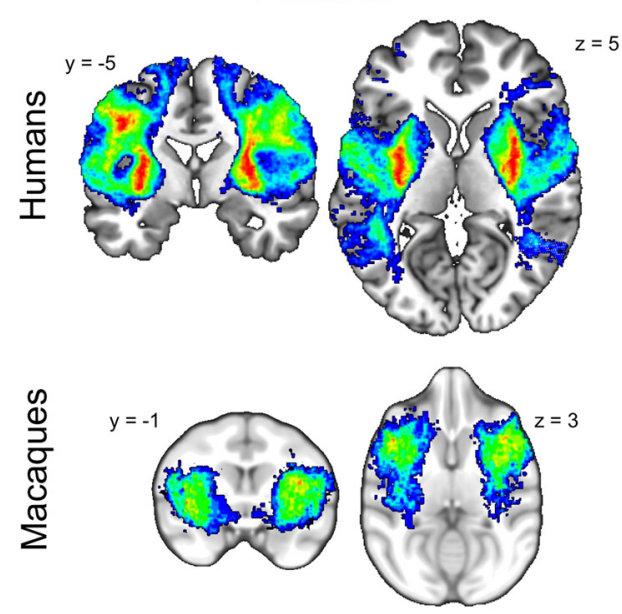

Globus Pallidus
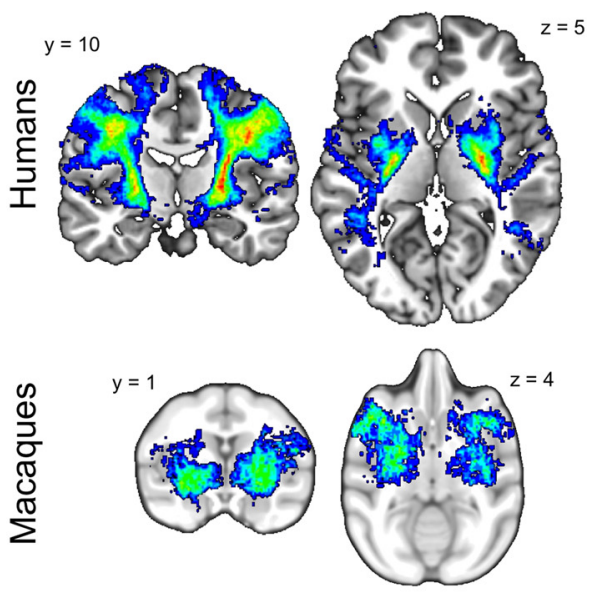

Macaque LMC tracer connections
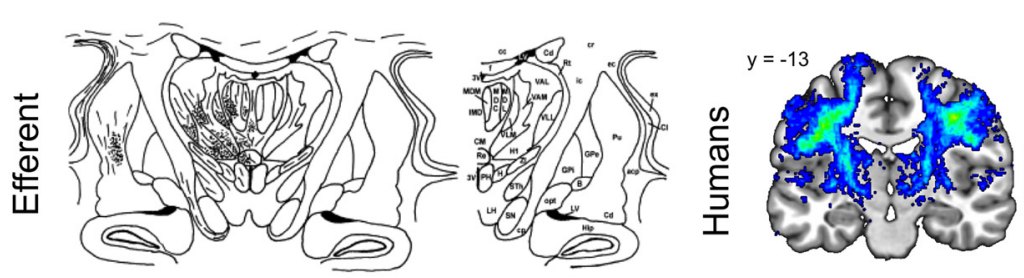

Thalamus
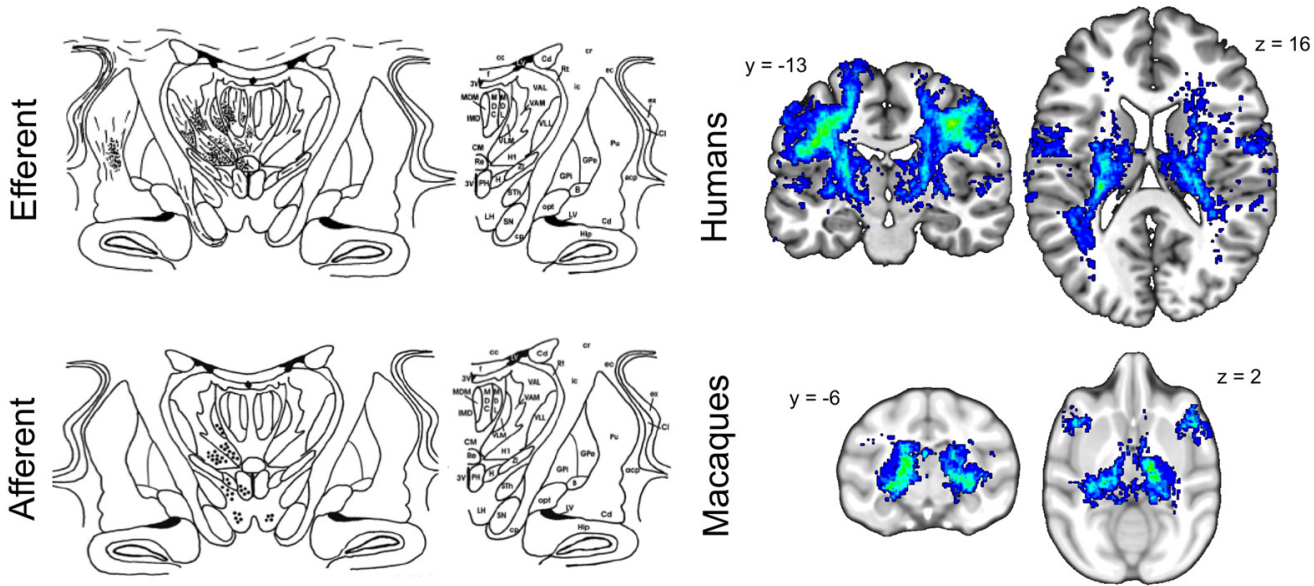

0.2

1.0

Figure 3. Probabilistic maps of structural connectivity between the LMC and subcortical regions known to be involved in voice control. Probabilistic tractography maps in humans and macaques are depicted on a series of coronal and axial brain slices in the standard space. These maps illustrate the spectrum of connection likelihood, or probability, of the tract distribution across subjects within each group. The corresponding color bar shows the probabilistic distribution of structural connections having a pathway pass through a given brain region thresholded from 0.2 (a low connection probability) to 1 (a high connection probability) in both species. For a visual comparison between the findings of probabilistic tractography and neuroanatomical tract tracing of the LMC, schematic diagrams of the rhesus monkey subcortical structures depict lines and dots as probabilistic distribution of the anterograde and retrograde projections of the macaque LMC (adapted from Simonyan and Jürgens, 2003, 2005b). The corresponding MNI coordinates of the center of gravity of maximal tract probability within each target region in each species is given in Table 2. 
Table 2. Center of gravity of maximal tract probability within each target region in the human and monkey

\begin{tabular}{|c|c|c|c|c|c|c|}
\hline \multirow[b]{2}{*}{ Target brain region } & \multicolumn{3}{|c|}{ Humans } & \multicolumn{3}{|c|}{ Macaques } \\
\hline & $x$ & $y$ & $z$ & $x$ & $y$ & $z$ \\
\hline \multicolumn{7}{|c|}{ Primary somatosensory cortex (areas 3a, 3b, 1, 2) } \\
\hline Right & 58 & -4 & 16 & 21 & -1 & 8 \\
\hline \multicolumn{7}{|l|}{ IFG area 44} \\
\hline Left & -51 & 9 & 12 & -20 & 9 & -1 \\
\hline Right & 54 & 10 & 7 & 20 & 11 & 1 \\
\hline Right & 55 & 23 & 15 & 16 & 14 & 2 \\
\hline \multicolumn{7}{|l|}{ IPL area 40, PF } \\
\hline Left & -43 & -54 & 29 & -21 & -10 & 9 \\
\hline Right & 44 & -52 & 32 & 20 & -11 & 10 \\
\hline \multicolumn{7}{|l|}{ STG areas $41,42,22$} \\
\hline Left & -41 & -4 & 0 & -21 & -2 & -5 \\
\hline \multicolumn{7}{|c|}{$\mathrm{ACC}$ areas $25,33,24,32$} \\
\hline Left & -8 & 34 & 25 & -2 & 11 & 8 \\
\hline Right & 8 & 19 & 22 & 2 & 13 & 9 \\
\hline \multicolumn{7}{|c|}{ MCC areas $33^{\prime}, 24^{\prime}, 24 d, 32^{\prime}$} \\
\hline Left & -6 & -15 & 33 & -6 & -5 & 13 \\
\hline Right & 12 & 20 & 45 & 4 & -5 & 13 \\
\hline \multicolumn{7}{|l|}{ Putamen } \\
\hline Left & -31 & -11 & -1 & -13 & 3 & -7 \\
\hline Right & 31 & -13 & 5 & 11 & 3 & -8 \\
\hline \multicolumn{7}{|l|}{ Caudate nucleus } \\
\hline Left & -20 & 17 & 9 & -6 & 9 & 4 \\
\hline Right & 7 & 6 & 0 & 4 & 7 & 4 \\
\hline \multicolumn{7}{|c|}{ Globus pallidus (both internal and external subdivisions) } \\
\hline
\end{tabular}

For comparability, all coordinates are given in the standard MNI space of the standard human brain and standard monkey brain, respectively.

to laryngeal motoneurons and enabling the voluntary control of laryngeal movements for highly learned behaviors such as human speech (Jürgens, 2002; Simonyan and Jürgens, 2003; Brown et al., 2008; Simonyan, 2014). However, it remained unclear whether any other additional changes in long-range LMC connectivity may have played any role in the development of enhanced control of speech motor output by the human LMC compared with its functional homolog in the macaque.

We addressed this question by demonstrating that, despite similarities in overall structural network organization in the two species, the human LMC network established strong connections with cortical brain regions specifically involved in the processing of sensory information and feedback (primary somatosensory cortex, STG), planning of motor sequences (IFG, SMA), and sensorimotor integration (IPL), whereas connections to these regions within the macaque LMC network were fewer and largely limited to the IFG and STG only.

Specifically, we found that the contribution of primary somatosensory cortex and IPL to the human LMC network was nearly 7 -fold larger (71.1\% of all LMC connections in humans) than to the macaque LMC (only 10.7\%). In fact, IPL showed the highest connections of any ROI with the human LMC network, but showed only moderate connections within the macaque LMC network. This represents a remarkable development of LMC cortical connectivity in humans, especially taking into account that the IPL and somatosensory cortex are important for integrating sensory feedback and adjusting speech parameters during speaking, with IPL coordinating speech production, comprehension, and monitoring verbal responses to suppress phonemic errors (Price, 2012; Pandey and Heilman, 2014). Further, the IPL is recruited preferentially in the speech production network, but not the resting-state network (Simonyan and Fuertinger, 2015), whereas damage to the IPL produces receptive aphasia, destroying the ability to understand language and speak meaningfully (Kertesz et al., 1982; Alexander et al., 1989; Hart and Gordon, 1990). Altogether, strong connectivity of the human LMC with the parietal cortex may point to the complex synchrony of higher-order sensorimotor coordination, proprioceptive and tactile feedback, and modulation of learned voice characteristic for speech, but not innate, species-specific monkey calls.

Similar to the IPL, the human LMC-STG connections were more widely distributed along the rostrocaudal axis, although the STG had greater contribution to the macaque LMC network (7.2\% vs $4.7 \%$ of all examined LMC tracts). This finding may be explained by increased temporal and modulatory demands of speech production, as well as the importance of auditory feedback for speech monitoring and error detection compared with the production of more genetically preprogrammed innate vocalization (Guenther, 2006; Peschke et al., 2009). It is likely that the distribution of STG-LMC connections, as well as their tendency 


\section{Humans}
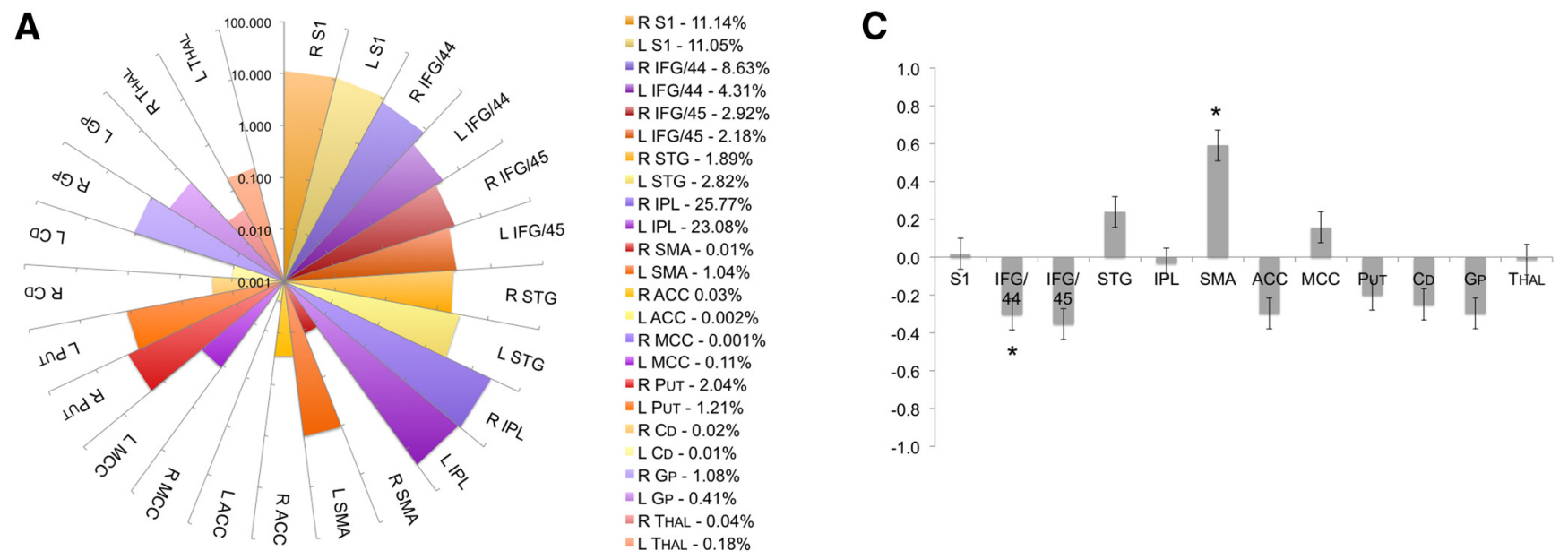

\section{Macaques}

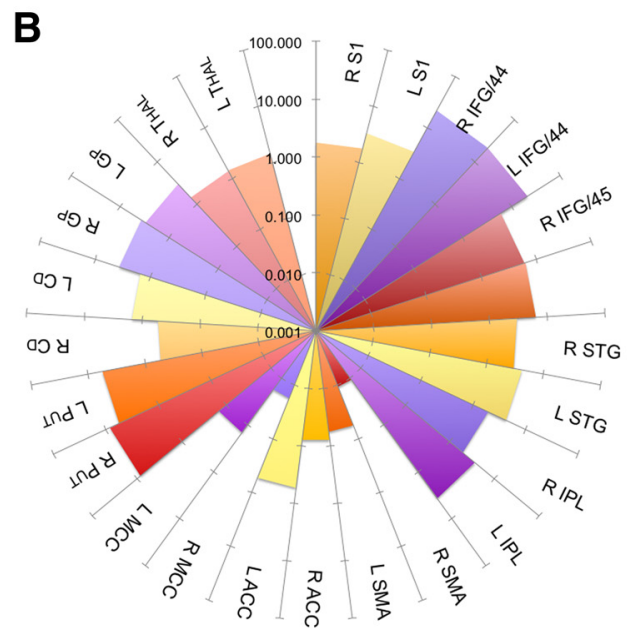
$=\mathrm{R} \mathrm{S1}-1.76 \%$
L S $1-3.35 \%$
= R IFG/44 - $21.61 \%$
- L IFG $/ 44-21.51 \%$
= R IFG $/ 45-6.14 \%$
$=\mathrm{LIFG} / 45-6.41 \%$
$=$ R STG $-3.02 \%$
- LSTG - $4.16 \%$
$=$ RIPL $-1.94 \%$
RIPL- $1.94 \%$
= R SMA - $0.01 \%$
$=$ L SMA - $0.06 \%$
$=$ R ACC $0.08 \%$
LACC - $0.54 \%$
= R MCC $-0.02 \%$
- $L$ MCC $-0.15 \%$
-R PUT $-8.35 \%$
- L PUT $-5.62 \%$
R CD $-0.53 \%$
LCD $-1.52 \%$
$=R \mathrm{RP}-3.69 \%$
- R GP - $3.69 \%$
R THAL $-1.41 \%$
$=$ L THAL $-1.43 \%$

\section{D}

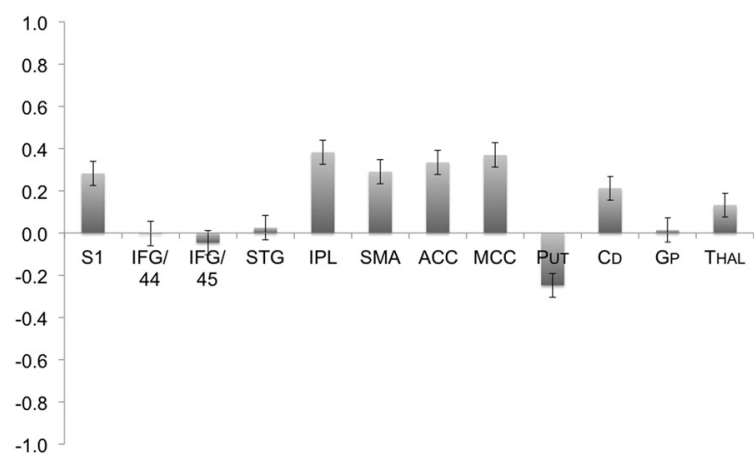

Figure 4. Quantitative distribution of within-species LMC connections. $A, B$, Connectivity fingerprints show the proportion (\%, in logarithmic scale) of $L M C$ tracts reaching each target region in humans and macaques. The corresponding percentage of each tract contribution is given on the right. $C, D, B a r$ graphs depict the hemispheric laterality indices of $L M C-$ target connections in humans and macaques. Asterisk (*) in ( marks human LMC connections to area 44 and SMA, which showed significant lateralization between the hemispheres; the STG showed a trend to lateralization. No significant hemispheric lateralization of the LMC tracts was identified in macaques. Values $>0$ indicate left-hemispheric lateralization; values $<0$ indicate right-hemispheric lateralization. Error bars indicate SE. S1, Primary somatosensory cortex; Put, putamen; Cd, caudate nucleus; Gp, globus pallidus; Thal, thalamus.

to left lateralization, may reflect the complexity of speech perception in humans and the importance of LMC not only in motor integration but also in auditory processing (Wilson et al., 2004; Möttönen and Watkins, 2009).

It is worth noting that enhanced frontoparietal connectivity through the arcuate fasciculus may have also played a key role in speech evolution. Neuroimaging studies revealed that the arcuate fasciculus is critical in processing of syntax and lexical semantics (López-Barroso et al., 2013) and that temporal projections of the arcuate fasciculus to IFG, which dominate the human pathway, are virtually absent in nonhuman primates (Catani et al., 2005; Rilling et al., 2008; Petrides and Pandya, 2009). Notably, chimpanzees appear to evolve a dorsal pathway dominated by connections with the IPL, in contrast to the ventral extreme capsule pathway found in macaques (Rilling et al., 2008; Rilling et al., 2012). This may explain their capacity for certain volitional calls. Because the IPL is important for the transformation of word representations stored in Wernicke's area into verbal motor patterns via proprioceptive feedback (Cappa et al., 1981; Jürgens, 2002), it is possible that the evolution of the arcuate fasciculus might have occurred concurrently with the development of enhanced LMC-temporoparietal pathways to allow for the formation of word representations and production of voluntary vocalizations.

Conversely, there were a few regions that showed similar connectivity within both human and macaque LMC networks. One of these regions was the IFG, including its bilateral area 44 and right area 45 (Broca's area). Based on electrophysiological and neuroimaging studies, the IFG is functionally coupled with LMC (Greenlee et al., 2004; Simonyan et al., 2009) and is thought to be crucial for articulatory and semantic preparations to speaking, being activated during both speech perception and production (Price et al., 1996; Schlösser et al., 1998; Silbert et al., 2014). Because of the importance of the IFG for higher-order speech control, it is more active during longer sequences (Wise et al., 1999; Horwitz et al., 2003) than during single syllables (Loucks et al., 2007; Ghosh et al., 2008). The role of this region in the control of voice production in other species than humans remains unclear (Ackermann et al., 2014) because it does not exhibit 
population-level hemispheric asymmetry in chimpanzees (Schenker et al., 2010) and its lesions do not impair monkey vocalizations (Jürgens et al., 1982). However, the ventrolateral prefrontal cortex controls audio-vocal interaction in species-specific monkey vocalizations, potentially providing the relay station between higher-order auditory processing and vocal output (Hage and Nieder, 2015), whereas its electrical stimulation produces orofacial responses, suggesting its contribution to the sensory encoding of vocalizations (Petrides et al., 2005; Hage and Nieder, 2015). Furthermore, IFG recruitment for orofacial expressions and volitional calls in the chimpanzee points to its importance in vocal communication before the divergence of chimpanzees and humans (Hopkins et al., 2007; Taglialatela et al., 2008; Rilling, 2014). Our findings suggest that, despite being unable to produce speech, monkeys may still exhibit complex vocal regulation due to enhanced LMC-IFG projections that are highly similar to those in humans.

Another similarity in LMC structural connectivity within human and macaque species was observed in subcortical structures. Based on neuroanatomical tract tracing studies in macaques, the heaviest LMC subcortical projections reach the putamen, with other direct projections scattered in various subcortical regions (Simonyan and Jürgens, 2003, 2005a). Our study replicated these tracer studies in macaques and further confirmed the presence of similar connections in humans using probabilistic tractography, collectively suggesting that subcortical pathways, in addition to the direct corticobulbar pathway, may play an important role in the control of laryngeal functions. The putamen exhibits a wide range of modulatory influences on learned voice control, including speech initiation, production, and tempo, as well as syntactic and semantic processing, emotional speech prosody, verbal semantic and episodic memory, and vocal imitation of novel speech sequences (Price, 2012). Conversely, putaminal lesions have little, if any, effect on monkey vocalizations and electrical stimulation of the striatum fails to initiate vocalizations in nonhuman primates (Jürgens and Ploog, 1970), which indicates that the putamen may have a greater role in the control of learned than innate voice production (Jürgens, 2002). Such functional discrepancy in the structurally similar LMC-striatal networks in humans and macaques points to a lack of functional maturity of this circuitry in macaques, possibly representing another evolutionary leap contributing to enhanced control of vocal motor output.

Speech production is widely considered to have lefthemispheric dominance (Morillon et al., 2010; Findlay et al., 2012; Gehrig et al., 2012; Peelle, 2012). This notion, however, has been challenged in recent years because electrocorticography and neuroimaging studies identified bilateral sensorimotor transformations and network interactions during speech production, comprehension, feedback error detection, and rate prediction (Cogan et al., 2014; Silbert et al., 2014; Simonyan and Fuertinger, 2015). We have proposed that, although large-scale functional brain networks may exert bilateral control of different aspects of speech production, hemispheric lateralization of only a few subnetworks may be required for a more efficient information transfer across the speech production network (Simonyan and Fuertinger, 2015). Our current study demonstrated left lateralization of only two of 12 human LMC target connections, suggesting that the structural network of speech motor control may represent a "hard-wired" framework, upon which the functional speech motor network is built. In contrast, we found no significant lateralization of LMC tracts in macaques. This is consistent with the limited involvement of the LMC in the control of leaned vocalizations (Jürgens, 2002; Coudé et al., 2011; Simonyan,
2014), and thus much reduced demands to establish influential, within-hemispheric connectivity for faster information flow.

In conclusion, our findings indicate that LMC structural networks in humans and nonhuman primates are largely similar, suggesting that many of the neural systems underlying human speech evolved from a foundation that already existed in nonhuman primates. This is particularly true of subcortical regions and even in the regions highly involved in human speech control, such as Broca's area. Conversely, key differences were noted in LMC structural networks, including enhanced connectivity with the temporoparietal regions in humans, which might have allowed for more active sensorimotor integration with the motor pathways originating from the LMC. Together, our data point to the importance of understanding of LMC structural networks when considering the development of speech motor control.

\section{References}

Ackermann H, Hage SR, Ziegler W (2014) Brain mechanisms of acoustic communication in humans and nonhuman primates: an evolutionary perspective. Behav Brain Sci 37:529-546. CrossRef Medline

Alexander MP, Hiltbrunner B, Fischer RS (1989) Distributed anatomy of transcortical sensory aphasia. Arch Neurol 46:885-892. CrossRef Medline

Andersson JL, Skare S, Ashburner J (2003) How to correct susceptibility distortions in spin-echo echo-planar images: application to diffusion tensor imaging. Neuroimage 20:870-888. CrossRef Medline

Bohland JW, Guenther FH (2006) An fMRI investigation of syllable sequence production. Neuroimage 32:821-841. CrossRef Medline

Bouchard KE, Mesgarani N, Johnson K, Chang EF (2013) Functional organization of human sensorimotor cortex for speech articulation. Nature 495:327-332. CrossRef Medline

Breshears JD, Molinaro AM, Chang EF (2015) A probabilistic map of the human ventral sensorimotor cortex using electrical stimulation. J Neurosurg 123:340-349. CrossRef Medline

Brown S, Ngan E, Liotti M (2008) A larynx area in the human motor cortex. Cereb Cortex 18:837-845. CrossRef Medline

Brown S, Laird AR, Pfordresher PQ, Thelen SM, Turkeltaub P, Liotti M (2009) The somatotopy of speech: phonation and articulation in the human motor cortex. Brain Cogn 70:31-41. CrossRef Medline

Campbell JS, Pike GB (2014) Potential and limitations of diffusion MRI tractography for the study of language. Brain Lang 131:65-73. CrossRef Medline

Cappa S, Cavallotti G, Vignolo LA (1981) Phonemic and lexical errors in fluent aphasia: correlation with lesion site. Neuropsychologia 19:171177. CrossRef Medline

Catani M, Jones DK, ffytche DH (2005) Perisylvian language networks of the human brain. Ann Neurol 57:8-16. CrossRef Medline

Cerliani L, Thomas RM, Jbabdi S, Siero JC, Nanetti L, Crippa A, Gazzola V, D’Arceuil H, Keysers C (2012) Probabilistic tractography recovers a rostrocaudal trajectory of connectivity variability in the human insular cortex. Hum Brain Mapp 33:2005-2034. CrossRef Medline

Chang SE, Kenney MK, Loucks TM, Poletto CJ, Ludlow CL (2009) Common neural substrates support speech and non-speech vocal tract gestures. Neuroimage 47:314-325. CrossRef Medline

Cogan GB, Thesen T, Carlson C, Doyle W, Devinsky O, Pesaran B (2014) Sensory-motor transformations for speech occur bilaterally. Nature 507: 94-98. CrossRef Medline

Colby JB, Soderberg L, Lebel C, Dinov ID, Thompson PM, Sowell ER (2012) Along-tract statistics allow for enhanced tractography analysis. Neuroimage 59:3227-3242. CrossRef Medline

Coudé G, Ferrari PF, Rodà F, Maranesi M, Borelli E, Veroni V, Monti F, Rozzi S, Fogassi L (2011) Neurons controlling voluntary vocalization in the macaque ventral premotor cortex. PLoS One 6:e26822. CrossRef Medline

Eckers C, Kroger BJ, Sass K, Heim S (2013) Neural representation of the sensorimotor speech-action-repository. Front Hum Neurosci 7:121. CrossRef Medline

Eickhoff SB, Stephan KE, Mohlberg H, Grefkes C, Fink GR, Amunts K, Zilles K (2005) A new SPM toolbox for combining probabilistic cytoarchitectonic maps and functional imaging data. Neuroimage 25:1325-1335. CrossRef Medline 
Eickhoff SB, Bzdok D, Laird AR, Kurth F, Fox PT (2012) Activation likelihood estimation meta-analysis revisited. Neuroimage 59:2349-2361. CrossRef Medline

Findlay AM, Ambrose JB, Cahn-Weiner DA, Houde JF, Honma S, Hinkley LB, Berger MS, Nagarajan SS, Kirsch HE (2012) Dynamics of hemispheric dominance for language assessed by magnetoencephalographic imaging. Ann Neurol 71:668-686. CrossRef Medline

Foerster O (1936) Motorische Felder und Bahnen. In: Hanbuch der Neurologie (Bumke O, Foerster O, eds). Berlin: Springer.

Frey S, Pandya DN, Chakravarty MM, Bailey L, Petrides M, Collins DL (2011) An MRI based average macaque monkey stereotaxic atlas and space (MNI monkey space). Neuroimage 55:1435-1442. CrossRef Medline

Fuertinger S, Horwitz B, Simonyan K (2015) The functional connectome of speech control. PLoS Biol 13:e1002209. CrossRef Medline

Gehrig J, Wibral M, Arnold C, Kell CA (2012) Setting up the speech production network: how oscillations contribute to lateralized information routing. Front Psychol 3:169. Medline

Ghosh SS, Tourville JA, Guenther FH (2008) A neuroimaging study of premotor lateralization and cerebellar involvement in the production of phonemes and syllables. J Speech Lang Hear Res 51:1183-1202. CrossRef Medline

Grabski K, Lamalle L, Vilain C, Schwartz JL, Vallée N, Tropres I, Baciu M, Le Bas JF, Sato M (2012) Functional MRI assessment of orofacial articulators: neural correlates of lip, jaw, larynx, and tongue movements. Hum Brain Mapp 33:2306-2321. CrossRef Medline

Greenlee JD, Oya H, Kawasaki H, Volkov IO, Kaufman OP, Kovach C, Howard MA, Brugge JF (2004) A functional connection between inferior frontal gyrus and orofacial motor cortex in human. J Neurophysiol 92: 1153-1164. CrossRef Medline

Guenther FH (2006) Cortical interactions underlying the production of speech sounds. J Commun Disord 39:350-365. CrossRef Medline

Hage SR, Nieder A (2015) Audio-vocal interaction in single neurons of the monkey ventrolateral prefrontal cortex. J Neurosci 35:7030-7040. CrossRef Medline

Hart J Jr, Gordon B (1990) Delineation of single-word semantic comprehension deficits in aphasia, with anatomical correlation. Ann Neurol 27: 226-231. CrossRef Medline

Hast MH, Fischer JM, Wetzel AB, Thompson VE (1974) Cortical motor representation of the laryngeal muscles in Macaca mulatta. Brain Res 73:229-240. CrossRef Medline

Hickok G, Poeppel D (2007) The cortical organization of speech processing. Nat Rev Neurosci 8:393-402. CrossRef Medline

Hopkins WD, Taglialatela J, Leavens DA (2007) Chimpanzees differentially produce novel vocalizations to capture the attention of a human. Anim Behav 73:281-286. CrossRef Medline

Horwitz B, Amunts K, Bhattacharyya R, Patkin D, Jeffries K, Zilles K, Braun AR (2003) Activation of Broca's area during the production of spoken and signed language: a combined cytoarchitectonic mapping and PET analysis. Neuropsychologia 41:1868-1876. CrossRef Medline

Iwatsubo T, Kuzuhara S, Kanemitsu A, Shimada H, Toyokura Y (1990) Corticofugal projections to the motor nuclei of the brainstem and spinal cord in humans. Neurology 40:309-312. CrossRef Medline

Jbabdi S, Johansen-Berg H (2011) Tractography: where do we go from here? Brain Connect 1:169-183. CrossRef Medline

Jbabdi S, Lehman JF, Haber SN, Behrens TE (2013) Human and monkey ventral prefrontal fibers use the same organizational principles to reach their targets: tracing versus tractography. J Neurosci 33:3190-3201. CrossRef Medline

Johansen-Berg H, Behrens TE (2006) Just pretty pictures? What diffusion tractography can add in clinical neuroscience. Curr Opin Neurol 19:379385. CrossRef Medline

Jürgens U (1974) On the elicitability of vocalization from the cortical larynx area. Brain Res 81:564-566. CrossRef Medline

Jürgens U (1976) Projections from the cortical larynx area in the squirrel monkey. Exp Brain Res 25:401-411. Medline

Jürgens U (2002) Neural pathways underlying vocal control. Neurosci Biobehav Rev 26:235-258. CrossRef Medline

Jürgens U, Ploog D (1970) Cerebral representation of vocalization in the squirrel monkey. Exp Brain Res 10:532-554. Medline

Jürgens U, Kirzinger A, von Cramon D (1982) The effects of deep-reaching lesions in the cortical face area on phonation. A combined case report and experimental monkey study. Cortex 18:125-139. CrossRef Medline

Kertesz A, Sheppard A, MacKenzie R (1982) Localization in transcortical sensory aphasia. Arch Neurol 39:475-478. CrossRef Medline

Kuypers HG (1958) Corticobular connexions to the pons and lower brainstem in man: an anatomical study. Brain 81:364-388. CrossRef Medline

Lewis JW, Van Essen DC (2000) Corticocortical connections of visual, sensorimotor, and multimodal processing areas in the parietal lobe of the macaque monkey. J Comp Neurol 428:112-137. CrossRef Medline

López-Barroso D, Catani M, Ripollés P, Dell'Acqua F, Rodríguez-Fornells A, de Diego-Balaguer R (2013) Word learning is mediated by the left arcuate fasciculus. Proc Natl Acad Sci U S A 110:13168-13173. CrossRef Medline

Lotze M, Seggewies G, Erb M, Grodd W, Birbaumer N (2000) The representation of articulation in the primary sensorimotor cortex. Neuroreport 11:2985-2989. Medline

Loucks TM, Poletto CJ, Simonyan K, Reynolds CL, Ludlow CL (2007) Human brain activation during phonation and exhalation: Common volitional control for two upper airway functions. Neuroimage 36:131-143. CrossRef Medline

Morillon B, Lehongre K, Frackowiak RS, Ducorps A, Kleinschmidt A, Poeppel D, Giraud AL (2010) Neurophysiological origin of human brain asymmetry for speech and language. Proc Natl Acad Sci U S A 107: 18688-18693. CrossRef Medline

Möttönen R, Watkins KE (2009) Motor representations of articulators contribute to categorical perception of speech sounds. J Neurosci 29:98199825. CrossRef Medline

Olthoff A, Baudewig J, Kruse E, Dechent P (2008) Cortical sensorimotor control in vocalization: a functional magnetic resonance imaging study. Laryngoscope 118:2091-2096. CrossRef Medline

Pandey AK, Heilman KM (2014) Conduction aphasia with intact visual object naming. Cogn Behav Neurol 27:96-101. CrossRef Medline

Paxinos G, Huang XF, Toga AW (2000) The rhesus monkey brain in stereotaxic coordinates. San Diego: Academic.

Peelle JE (2012) The hemispheric lateralization of speech processing depends on what "speech" is: a hierarchical perspective. Front Hum Neurosci 6:309. Medline

Peeva MG, Guenther FH, Tourville JA, Nieto-Castanon A, Anton JL, Nazarian B, Alario FX (2010) Distinct representations of phonemes, syllables, and supra-syllabic sequences in the speech production network. Neuroimage 50:626-638. CrossRef Medline

Penfield W, Boldrey E (1937) Somatic motor and sensory representation in the cerebral cortex of man as studied by electrical stimulation. Brain 60:389-443. CrossRef

Penfield W, Roberts L (1959) Speech and brain mechanisms. Princeton, NJ: Princeton University.

Peschke C, Ziegler W, Kappes J, Baumgaertner A (2009) Auditory-motor integration during fast repetition: the neuronal correlates of shadowing. Neuroimage 47:392-402. CrossRef Medline

Petrides M, Pandya DN (2009) Distinct parietal and temporal pathways to the homologues of Broca's area in the monkey. PLoS Biol 7:e1000170. CrossRef Medline

Petrides M, Cadoret G, Mackey S (2005) Orofacial somatomotor responses in the macaque monkey homologue of Broca's area. Nature 435:12351238. CrossRef Medline

Price CJ (2012) A review and synthesis of the first 20 years of PET and fMRI studies of heard speech, spoken language and reading. Neuroimage 62: 816-847. CrossRef Medline

Price CJ, Moore CJ, Humphreys GW, Frackowiak RS, Friston KJ (1996) The neural regions sustaining object recognition and naming. Proc Biol Sci 263:1501-1507. CrossRef Medline

Ramsay SC, Adams L, Murphy K, Corfield DR, Grootoonk S, Bailey DL, Frackowiak RS, Guz A (1993) Regional cerebral blood flow during volitional expiration in man: a comparison with volitional inspiration. J Physiol 461:85-101. CrossRef Medline

Rathelot JA, Strick PL (2009) Subdivisions of primary motor cortex based on cortico-motoneuronal cells. Proc Natl Acad Sci U S A 106:918-923. CrossRef Medline

Reveley C, Seth AK, Pierpaoli C, Silva AC, Yu D, Saunders RC, Leopold DA, Ye FQ (2015) Superficial white matter fiber systems impede detection of long-range cortical connections in diffusion MR tractography. Proc Natl Acad Sci U S A 112:E2820-E2828. CrossRef Medline 
Riecker A, Ackermann H, Wildgruber D, Meyer J, Dogil G, Haider H, Grodd W (2000) Articulatory/phonetic sequencing at the level of the anterior perisylvian cortex: a functional magnetic resonance imaging (fMRI) study. Brain Lang 75:259-276. CrossRef Medline

Riecker A, Wildgruber D, Dogil G, Grodd W, Ackermann H (2002) Hemispheric lateralization effects of rhythm implementation during syllable repetitions: an fMRI study. Neuroimage 16:169-176. CrossRef Medline

Riecker A, Brendel B, Ziegler W, Erb M, Ackermann H (2008) The influence of syllable onset complexity and syllable frequency on speech motor control. Brain Lang 107:102-113. CrossRef Medline

Rilling JK (2014) Comparative primate neurobiology and the evolution of brain language systems. Curr Opin Neurobiol 28:10-14. CrossRef Medline

Rilling JK, Glasser MF, Preuss TM, Ma X, Zhao T, Hu X, Behrens TE (2008) The evolution of the arcuate fasciculus revealed with comparative DTI. Nat Neurosci 11:426-428. CrossRef Medline

Rilling JK, Scholz J, Preuss TM, Glasser MF, Errangi BK, Behrens TE (2012) Differences between chimpanzees and bonobos in neural systems supporting social cognition. Soc Cogn Affect Neurosci 7:369-379. CrossRef Medline

Rödel RM, Olthoff A, Tergau F, Simonyan K, Kraemer D, Markus H, Kruse E (2004) Human cortical motor representation of the larynx as assessed by transcranial magnetic stimulation (TMS). Laryngoscope 114:918-922. CrossRef Medline

Schenker NM, Hopkins WD, Spocter MA, Garrison AR, Stimpson CD, Erwin JM, Hof PR, Sherwood CC (2010) Broca's area homologue in chimpanzees (Pan troglodytes): probabilistic mapping, asymmetry, and comparison to humans. Cereb Cortex 20:730-742. CrossRef Medline

Schlösser R, Hutchinson M, Joseffer S, Rusinek H, Saarimaki A, Stevenson J, Dewey SL, Brodie JD (1998) Functional magnetic resonance imaging of human brain activity in a verbal fluency task. J Neurol Neurosurg Psychiatry 64:492-498. CrossRef Medline

Seghier ML (2008) Laterality index in functional MRI: methodological issues. Magn Reson Imaging 26:594-601. CrossRef Medline

Shuster LI (2009) The effect of sublexical and lexical frequency on speech production: an fMRI investigation. Brain Lang 111:66-72. CrossRef Medline

Silbert LJ, Honey CJ, Simony E, Poeppel D, Hasson U (2014) Coupled neural systems underlie the production and comprehension of naturalistic narrative speech. Proc Natl Acad Sci U S A 111:E4687-4696. CrossRef Medline

Simonyan K (2014) The laryngeal motor cortex: its organization and connectivity. Curr Opin Neurobiol 28:15-21. CrossRef Medline

Simonyan K, Fuertinger S (2015) Speech networks at rest and in action: interactions between functional brain networks controlling speech production. J Neurophysiol 113:2967-2978. CrossRef Medline

Simonyan K, Jürgens U (2002) Cortico-cortical projections of the motorcortical larynx area in the rhesus monkey. Brain Res 949:23-31. CrossRef Medline

Simonyan K, Jürgens U (2003) Efferent subcortical projections of the laryngeal motorcortex in the rhesus monkey. Brain Res 974:43-59. CrossRef Medline

Simonyan K, Jürgens U (2005a) Afferent cortical connections of the motor cortical larynx area in the rhesus monkey. Neuroscience 130:133-149. CrossRef Medline
Simonyan K, Jürgens U (2005b) Afferent subcortical connections into the motor cortical larynx area in the rhesus monkey. Neuroscience 130:119131. CrossRef Medline

Simonyan K, Saad ZS, Loucks TM, Poletto CJ, Ludlow CL (2007) Functional neuroanatomy of human voluntary cough and sniff production. Neuroimage 37:401-409. CrossRef Medline

Simonyan K, Ostuni J, Ludlow CL, Horwitz B (2009) Functional but not structural networks of the human laryngeal motor cortex show left hemispheric lateralization during syllable but not breathing production. J Neurosci 29:14912-14923. CrossRef Medline

Smith SM, Jenkinson M, Woolrich MW, Beckmann CF, Behrens TE, Johansen-Berg H, Bannister PR, De Luca M, Drobnjak I, Flitney DE, Niazy RK, Saunders J, Vickers J, Zhang Y, De Stefano N, Brady JM, Matthews PM (2004) Advances in functional and structural MR image analysis and implementation as FSL. Neuroimage 23:S208-S219. CrossRef Medline

Soros P, Sokoloff LG, Bose A, McIntosh AR, Graham SJ, Stuss DT (2006) Clustered functional MRI of overt speech production. Neuroimage 32: 376-387. CrossRef Medline

Sugar O, Chusid JG, French JD (1948) A second motor cortex in the monkey, Macaca mulatta. J Neuropathol Exp Neurol 7:182-189. CrossRef Medline

Taglialatela JP, Russell JL, Schaeffer JA, Hopkins WD (2008) Communicative signaling activates 'Broca's' homolog in chimpanzees. Curr Biol 18: 343-348. CrossRef Medline

Taylor PA, Saad ZS (2013) FATCAT: (an efficient) Functional and Tractographic Connectivity Analysis Toolbox. Brain Connect 3:523-535. CrossRef Medline

Taylor PA, Cho KH, Lin CP, Biswal BB (2012) Improving DTI tractography by including diagonal tract propagation. PLoS One 7:e43415. CrossRef Medline

Terumitsu M, Fujii Y, Suzuki K, Kwee IL, Nakada T (2006) Human primary motor cortex shows hemispheric specialization for speech. Neuroreport 17:1091-1095. Medline

Thomas C, Ye FQ, Irfanoglu MO, Modi P, Saleem KS, Leopold DA, Pierpaoli C (2014) Anatomical accuracy of brain connections derived from diffusion MRI tractography is inherently limited. Proc Natl Acad Sci U S A 111:16574-16579. CrossRef Medline

Tremblay P, Dick AS, Small SL (2013) Functional and structural aging of the speech sensorimotor neural system: functional magnetic resonance imaging evidence. Neurobiol Aging 34:1935-1951. CrossRef Medline

van den Heuvel MP, de Reus MA, Feldman Barrett L, Scholtens LH, Coopmans FM, Schmidt R, Preuss TM, Rilling JK, Li L (2015) Comparison of diffusion tractography and tract-tracing measures of connectivity strength in rhesus macaque connectome. Hum Brain Mapp 36:30643075. CrossRef Medline

Van Essen DC, Drury HA, Dickson J, Harwell J, Hanlon D, Anderson CH (2001) An integrated software suite for surface-based analyses of cerebral cortex. J Am Med Inform Assoc 8:443-459. CrossRef Medline

Wilson SM, Saygin AP, Sereno MI, Iacoboni M (2004) Listening to speech activates motor areas involved in speech production. Nat Neurosci 7:701702. CrossRef Medline

Wise RJ, Greene J, Büchel C, Scott SK (1999) Brain regions involved in articulation. Lancet 353:1057-1061. CrossRef Medline 